\title{
Lycopene prevents sugar-induced morphological changes and modulates antioxidant status of human lens epithelial cells
}

\author{
Ipseeta Mohanty, Sujata Joshi, Deepa Trivedi, Sushma Srivastava and S. K. Gupta* \\ Department of Pharmacology, All India Institute of Medical Sciences, Ansari Nagar, New Delhi - 110029, India
}

(Received 28 July 2001 - Revised 15 April 2002 - Accepted 2 May 2002)

\begin{abstract}
Cataract is a multifactorial disease. Osmotic stress, together with weakened antioxidant defence mechanisms, is attributed to the changes observed in human diabetic cataract. Epidemiological studies provide evidence that nutritional antioxidants slow down the progression of cataract. The usefulness of lycopene, a dietary carotenoid, in the pathogenesis of human cataracts has not been studied so far. Since the epithelium is the metabolic unit of the lens, the effect of lycopene on galactose-induced morphological changes and antioxidant status of human lens epithelial cells (HLEC) in culture was evaluated in the present study. HLEC of fresh cadaver eyes obtained from an eye bank were cultured in medium supplemented with fetal calf serum $(200 \mathrm{ml} / \mathrm{l})$. On confluency, the cells were subcultured in medium containing either 30 mM-d-galactose or $30 \mathrm{mM}$-d-galactose + lycopene $(5,10$ or $20 \mu \mathrm{M})$ for $72 \mathrm{~h}$. The cells were observed under the phase-contrast microscope and transmssion electron microscope for any morphological changes and then harvested for the estimation of various biochemical variables. Malondialdeyde, glutathione and antioxidant enzymes were significantly altered in the control as compared with the normal cultures. Vacuolization was also observed in the presence of galactose. Addition of lycopene confers significant protection against these changes in HLEC.
\end{abstract}

Cataract: Human lens epithelial cells: Lycopene

Cataract is the leading cause of blindness worldwide. It is a multifactorial disease and free radicals as well as oxidative stress have been implicated in its pathogenesis (Spector, 1995). A number of studies indicate that in most cataracts the pathological process is triggered by an initial damage to the epithelial cell membrane by the reactive oxygen species generated in situ. The reactive oxygen species generated may result in damage to the lens DNA, oxidation of protein, oxidation of glutathione, lipid peroxidation, disulfide bond formation, protein unfolding with sulfhydryl group exposure, protein aggregation, protein insolubilization and loss of membrane transport function due to oxidation of membrane component such as $\mathrm{Na}^{+}, \mathrm{K}^{+}$-ATPase pump. The lens epithelial cells are the most metabolically active part of the lens and antioxidant enzymes are concentrated mainly in the epithelium (Bermbach et al. 1991).

Osmotic stress in the diabetic cataract has been suggested to be the initiating mechanism of sugar-induced cataract (Collier \& Small, 1993). A link between the osmotic and oxidative stress has been established through demonstration of weakened antioxidant defence potential of the system subjected to high sugar concentration (Miyoshi et al. 1999; Obrosova et al. 1999). It has been suggested that auto-oxidation of monosaccharides, leading to the formation of $\mathrm{H}_{2} \mathrm{O}_{2}$ and free radicals, induces oxidative stress under diabetic conditions (Wolff \& Dean, 1985). However, these studies are mainly confined to either isolated animal lenses maintained in organ culture in a high-sugar environment or to diabetic cataract models. Furthermore, certain antioxidants are shown to prevent sugar-induced cataract-type changes in the lens.

Lycopene is the major carotenoid present in the diet and provides the familiar red colour of tomato products. Studies suggest that lycopene is a more potent scavenger of singlet oxygen than other major dietary carotenoids (Di Mascio et al. 1989). Protective associations for cervical intraepithelial neoplasia, prostrate, gastric and lung cancers are already documented by virtue of its antioxidant property (Clinton, 1998). Carotenoids have been found to exhibit prevention against napthalene-induced cataract in rats (Jacques \& Chylack, 1991). Recently, studies on experimental rats have demonstrated that incorporation of lycopene

\footnotetext{
Abbreviations: CAT, catalase; GSHPx, glutathione peroxidase; GST, glutathione S-transferase; HLEC, human lens epithelial cells; MDA, malondialdehyde.

* Corresponding author: Professor S. K. Gupta, fax + 9111686 2663, email skgupta@hotmail.com
} 
into the diet retards the onset and progression of sugarinduced cataract (Pollock et al. 1996, 1999). However, the role of lycopene in sugar-induced cataracts in human subjects has not been investigated so far.

The present study has been undertaken on human lens epithelial cells (HLEC) with the aim of investigating the effect of galactose on the antioxidant status of these cells subjected to hypergalactosaemic conditions in culture. Furthermore, the potential of lycopene in protecting against the adverse effect of high galactose on HLEC morphology and biochemistry was also evaluated.

\section{Materials and methods}

Dulbecco's modified Eagle's medium was obtained from Hi Media Laboratories (Mumbai, India). Galactose was procured from Sigma Chemicals (St Louis, USA) and lycopene from Jagsonpal Pharmaceutics (New Delhi, India). Gentamicin was obtained from Fulford (Mumbai, India) and betadine from Vasistha Pharmaceuticals (New Delhi, India). Fetal calf serum was from Biological Industries (Hyderabad, India). All other reagents were of analytical grade.

Donor eyes were obtained from the eye bank at the Dr Rajendra Prasad Center for Ophthalmic Sciences, All India Institute of Medical Sciences, New Delhi, India. Eyes were donated to the eye bank for use in corneal transplantation. Eyes were brought in a moist chamber to the laboratory within $8 \mathrm{~h}$ of the death of the donor. In all, fifty-six eyes with normal transparent lenses from donors of age range 40-50 years were used for the present study.

\section{Dissection and monolayer culture}

The method of Reddy et al. (1988) for culture of HLEC was followed. The eyes were washed with gentamicin $(50 \mathrm{ml} / \mathrm{l})$ and betadine $(10 \mathrm{ml} / \mathrm{l})$ solution. The cornea and iris were completely removed with the help of corneal scissors and the lens was exposed. An incision was made at the peripheral margin of the lens. The capsule flap was cut into four pieces. Each explant was spread out on the lateral wall of the culture flask (Falcon flask, volume $50 \mathrm{ml}, 25 \mathrm{~mm}^{2}$ ) with the anterior epithelial layer facing upwards. Dulbecco's modified Eagle's medium $(4 \mathrm{ml})$ supplemented with fetal calf serum $(200 \mathrm{ml} / \mathrm{l})$ and antibiotics $(100 \mu \mathrm{g}$ streptomycin and $100 \mathrm{IU}$ penicillin/ml) was poured in the flask without disturbing the adhered capsule explant. In order to do this, the flask was first set on its end in the $\mathrm{CO}_{2}$ incubator so that the medium was located at the base of the prepared flask. The rising water vapour protects the tissue from drying, forming a wet chamber. After $1 \mathrm{~h}$ the flask was laid down so that the medium covered the epithelium, which was now firmly attached to the surface of the flask. The HLEC explants were incubated at $37^{\circ} \mathrm{C}$ in a $5 \% \mathrm{CO}_{2}$ atmosphere and the medium was changed twice per week.

\section{Subculture of human lens epithelial cells}

HLEC were observed for growth under the microscope. Upon observing confluency, the cells were subcultured. For this procedure, the medium was discarded and the confluent cells were treated with $1 \mathrm{ml}$ trypsin $(0.5 \mathrm{mg} / \mathrm{l})-$ EDTA $(0 \cdot 2 \mathrm{mg} / \mathrm{l})$ for $8 \mathrm{~min}$ and gently dissociated by pipetting with the addition of fresh medium (Reddy et al. 1991). Following dissociation, the cell number in each flask was determined using a haemocytometer after staining with Trypan Blue $(4 \mathrm{mg} / \mathrm{l})$ under a phase-contrast microscope (magnification $\times 10)$. HLEC $\left(10^{6}\right.$ cells $\left./ \mathrm{ml}\right)$ were transferred from primary culture into subsequent passages to maintain HLEC in culture.

For the present study, after trypsinization HLEC were distributed into different culture flasks $\left(10^{6}\right.$ cells/flask) to serve as normal, control and test group samples. In the normal group flasks, HLEC were incubated with Dulbecco's modified Eagle's medium + fetal calf serum $(200 \mathrm{ml} / \mathrm{l})$. In the control group flasks, $30 \mathrm{~mm}$-galactose was added to the medium. The culture medium in the test group was supplemented with $30 \mathrm{~mm}$-galactose and 5, 10 or $20 \mu \mathrm{M}$-lycopene. During incubation, the lycopene-enriched medium was changed every $6 \mathrm{~h}$. The stock solution of lycopene $(1 \mathrm{~mm})$ was prepared in absolute alcohol by vigorous shaking and was clear to the naked eye. The final concentration of alcohol in the culture medium was not more than $0.1 \mathrm{ml} / 1$ in all the three test subgroups of lycopene.

Flasks for all the groups were maintained in duplicate and incubated for $72 \mathrm{~h}$. After completion of the incubation period, one set of HLEC from normal, control and test group flasks were observed for any morphological changes under a light microscope (Nikon, Tokyo, Japan) and then processed for transmission electron microscopy (Phillips 410 LS; CA, USA). The other set was utilized for the estimation of biochemical variables.

\section{Electron microscopy}

The media in the flasks to be processed for transmission electron microscopy study was discarded. Medium (4 ml) containing an equal volume of fixative $(20 \mathrm{ml}$ glutaraldehyde/l $0.1 \mathrm{M}$-PBS) was added to the flask and kept undisturbed for $1 \mathrm{~h}$ at room temperature. The HLEC were then scrapped out using a Falcon scraper (NJ, USA) and centrifuged at $8000 \mathrm{~g}$ (Remi Instruments, Mumbai, India) for $15 \mathrm{~min}$. For studying these HLEC under transmission electron microscopy, a standard protocol for fixation, dehydration, sectioning and viewing, as described by Eguchi \& Okada (1971), was followed.

\section{Stability studies}

The stability of microcrystalline aqueous solution of lycopene (1 mM) in Dulbecco's modified Eagle's medium was tested by the spectrophotometric method of Stahl et al. (1993). Briefly, $1 \mathrm{ml}$ medium was drawn at 0,3 and $6 \mathrm{~h}$ and to 1 vol. lycopene microcrystalline solution 1 vol. 2-propanol was added and vigorously vortexed for $15 \mathrm{~s}$. Subsequently, 3 vol. $n$-hexane-dichloromethane (5: 1, $\mathrm{v} / \mathrm{v}$ ) containing $1.2 \mathrm{~mm}$-butylated hydroxytoluene was added and mixed by vigorous vortexing for $30 \mathrm{~s}$. The mixture was then centrifuged briefly for phase separation and the organic phase was read at $472 \mathrm{~nm}$. Freshly prepared lycopene standard was also run at 0,3 and $6 \mathrm{~h}$. The concentration of lycopene in the medium was calculated using 
molar absorption $1.85 \times 10^{5}$ optical density units. The concentration of lycopene at $0 \mathrm{~h}$ in the medium was considered as $100 \%$.

\section{Biochemical analyses}

The culture media in the other set of flasks were discarded and HLEC were washed with PBS. The cells were then removed by scraping with a Falcon scraper (NJ, USA), collected in an Eppendorf tube and centrifuged (Remi Instruments) at $8000 \mathrm{~g}$ for $10 \mathrm{~min}$. HLEC homogenate $\left(10^{6} / 100 \mu \mathrm{l}\right)$ was prepared in $50 \mathrm{~mm}$-phosphate buffer, pH 7, under cold conditions. A sample of this homogenate $(100 \mu \mathrm{l})$ was used for the estimation of malondialdehyde (MDA). A sample of homogenate was centrifuged (Remi Instruments) at $8000 \mathrm{~g}$ for $15 \mathrm{~min}$ at $4^{\circ} \mathrm{C}$ and the supernatant fraction obtained was used for the estimation of glutathione.

Estimation of glutathione. Glutathione estimation was done by the method described by Moron et al. (1979). A protein-free supernatant fraction was obtained by addition of equal volume of TCA $(100 \mathrm{~g} / \mathrm{l})$ to the HLEC homogenate and centrifuged (Remi Instruments) at $8000 \mathrm{~g}$ for 30 min. A sample of this supernatant fraction $(0.1 \mathrm{ml})$ was used for the estimation of glutathione. The volume of the reaction mixture was made up to $1 \mathrm{ml}$ with $0.3 \mathrm{M}$ $\mathrm{Na}_{2} \mathrm{HPO}_{4}(\mathrm{pH} 8)$ and colour was produced by the addition of $1.25 \mathrm{ml} 0.6 \mathrm{~mm}-5,5^{\prime}$ dithiobis(2-nitrobenzoic acid) prepared in trisodium citrate $(10 \mathrm{ml} / \mathrm{l})$. The absorbance of the resulting yellow colour was recorded within $10 \mathrm{~min}$ at $412 \mathrm{~nm}$ on a Beckman's spectrophotometer (Beckman Instruments, Minnesota, MN, USA). A parallel standard was also run to calculate the amount of glutathione in HLEC.

Estimation of malondialdehyde. MDA estimation was done in HLEC homogenate by the method described by Ohkawa et al. (1979). To 0.1 ml homogenate, 0.2 ml SDS $(81.0 \mathrm{~g} / \mathrm{l}), 1.5 \mathrm{ml}$ acetic acid $(200.0 \mathrm{~g} / \mathrm{l})$ and $1.5 \mathrm{ml}$ thiobarbituric acid $(8 \cdot 1 \mathrm{~g} / \mathrm{l})$ were added. The mixture was heated for $30 \mathrm{~min}$ at $95^{\circ} \mathrm{C}$ in a temperature-controlled waterbath. After cooling, $5 \mathrm{ml} n$-butanol pyridine $(15: 1 \mathrm{v} / \mathrm{v})$ was added to it. The mixture was centrifuged (Remi Instruments) at $8000 \mathrm{~g}$ for $10 \mathrm{~min}$. Absorbance of the organic layer was read spectrofluorimetrically at excitation wavelength $532 \mathrm{~nm}$ and emission wavelength $515 \mathrm{~nm}$. 1,1,3,3-tetraethoxypropane was used as standard to obtain a curve for the calculation of unknown MDA in the samples.

Estimation of antioxidant enzymes. For the estimation of antioxidant enzymes, HLEC homogenate $\left(10^{6} / 100 \mu \mathrm{l}\right)$ was prepared under cold conditions in $50 \mathrm{~mm}$-phosphate buffer, $\mathrm{pH} 7$, and centrifuged at $8000 \mathrm{~g}$ (Remi Instruments) for $15 \mathrm{~min}$ at $4^{\circ} \mathrm{C}$ and the supernatant fraction was used for the estimation of glutathione $S$-transferase (GST), glutathione peroxidase (GSHPx) and catalase (CAT) The effect of $10 \mu \mathrm{M}$-lycopene was evaluated on the activity of these antioxidant enzymes.

GST activity was measured by the method of Hebig (1974) at $250^{\circ} \mathrm{C}$. The conjugation of GST with 1-chloro2,4-dinitrobenzene, a hydrophilic substrate, was observed spectrophotometrically at $340 \mathrm{~nm}$. Briefly, the reaction mixture contained $1.7 \mathrm{ml} 100 \mathrm{mM}$-phosphate buffer $(\mathrm{pH}$ 6.5), $\quad 0.1 \mathrm{ml} 30 \mathrm{~mm}$-1-chloro-2,4-dinitrobenzene, $0.1 \mathrm{ml}$
$30 \mathrm{~mm}$ glutathione and $0.05 \mathrm{ml}$ HLEC supernatant fraction. The change in absorbance was recorded at $340 \mathrm{~nm}$ at $30 \mathrm{~s}$ intervals for $3 \mathrm{~min}$. One unit GST is defined as the amount of enzyme required to conjugate $1 \mu \mathrm{mol} 1$-chloro-2,4dinitrobenzene with glutathione/min.

CAT was estimated according to the method of Aebi (1974). For the estimation of $\mathrm{CAT}_{2} \mathrm{O}_{2}$ was used as substrate. The assay was conducted at $25^{\circ} \mathrm{C}$. The reaction mixture consisted of $1 \mathrm{ml} 50 \mathrm{mM}$-phosphate buffer $(\mathrm{pH} 7)$ and $0.05 \mathrm{ml}$ HLEC supernatant fraction. The change in the absorbance at $240 \mathrm{~nm}$ was followed at $5 \mathrm{~s}$ intervals for $30 \mathrm{~s}$, after the addition of $0.1 \mathrm{ml} 30 \mathrm{mM} \mathrm{H}_{2} \mathrm{O}_{2}$ against the sample blank. One unit of CAT activity represents the amount of enzyme required to decompose $1 \mu \mathrm{mol} \mathrm{H}_{2} \mathrm{O}_{2} / \mathrm{min}$.

GSHPx activity was measured by the method of Paglia \& Valentine (1967). GSHPx activity was monitored at $25^{\circ} \mathrm{C}$. Briefly, to $0.8 \mathrm{ml} 50 \mathrm{~mm}$-phosphate buffer $0.05 \mathrm{ml}$ each of $75 \mathrm{~mm}$-EDTA, $25 \mathrm{~mm}$-sodium azide, $250 \mathrm{~mm}$-glutathione, $7.5 \mathrm{~mm}-\mathrm{NADPH}$ and $0.05 \mathrm{ml}$ HLEC supernatant fraction were added. Then, 6 units glutathione reductase were added to this reaction mixture. Blank was set and the reaction was then started by the addition of $0.05 \mathrm{ml}$ $\mathrm{H}_{2} \mathrm{O}_{2}(0.075 \mathrm{~mm})$. The change in absorbance/min was recorded at $340 \mathrm{~nm}$ for $2 \mathrm{~min}$ at intervals of $15 \mathrm{~s}$. GSHPx activity was calculated from the extinction coefficient of NADPH. One unit GSHPx activity is defined as amount of enzyme required to utilize $1 \mathrm{nmol} \mathrm{NADPH} / \mathrm{min}$ at $37^{\circ} \mathrm{C}$.

Protein estimation. The method of Lowry et al. (1951) was followed for the estimation of protein levels in HLEC samples. The amount of protein was estimated per million cells.

\section{Statistical analysis}

The data were presented as mean values and standard devations. The number of samples in each group was six. Unpaired Student's $t$ test was applied to compare the results of the normal and the control group and probability value $P<0.05$ was regarded as statistically significant. ANOVA with post-hoc analysis (Bonferroni multiple range test) was applied to compare control and test groups.

\section{Results}

\section{Microscopic studies}

HLEC in primary culture took on an average $10-12 \mathrm{~d}$ to attain confluency. Normal HLEC appeared hexagonal in shape, had prominent nuclei and smooth cell margins under the phase-contrast microscope. The nucleus was mostly central and the cytoplasm uniformly distributed (Fig. 1)

Electron microscopy of normal HLEC showed demarcated cell membranes, cytoplasm and nuclei (Fig. 2). HLEC showed intracellular cytoplasmic vacuoles at $72 \mathrm{~h}$ incubation in the presence of galactose (Fig. 3). The mean value for the size of the vacuole observed in the presence of galactose at $72 \mathrm{~h}$ was $0.34(\mathrm{SD} 0.09) \mu \mathrm{m}$. Its volume and area were 0.021 (SD 0.003) $\mu \mathrm{m}^{3}$ and 0.37 (SD 0.08) $\mu^{2}$ respectively. Inclusion of $10 \mu \mathrm{M}$-lycopene to the culture medium containing $30 \mathrm{~mm}$-galactose decreased the size 


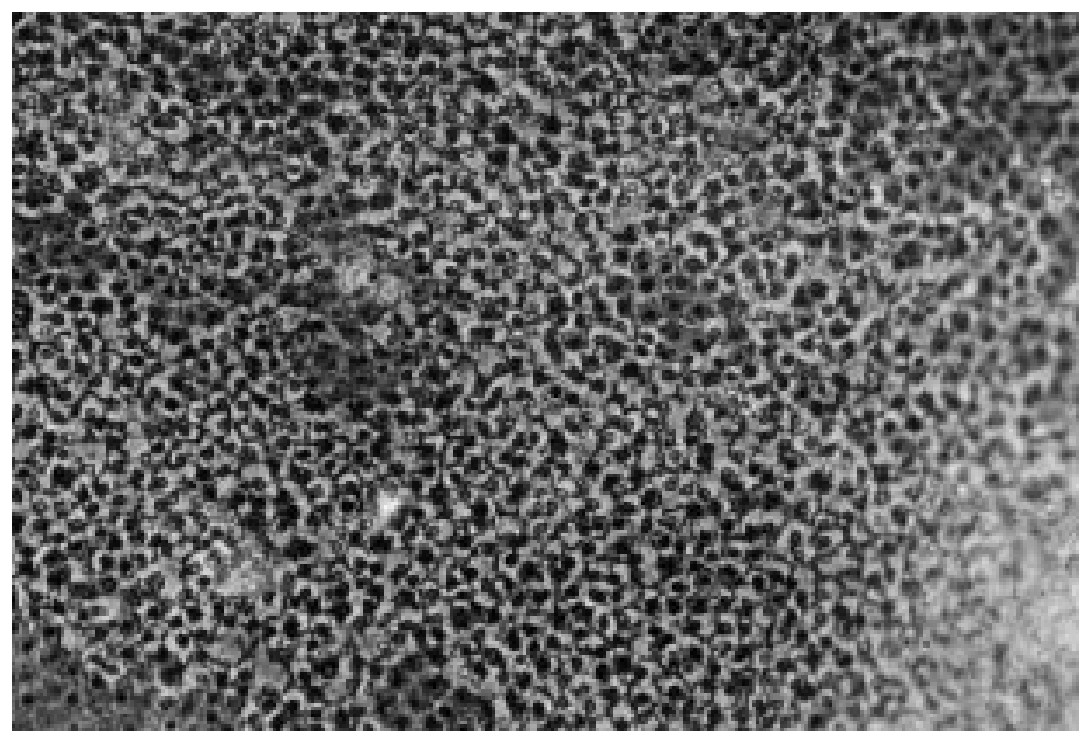

Fig. 1. Normal human lens epithelium cells under light microscope (magnification $\times 10)$. For details of procedures, see p. 348 .

of vacuoles significantly $(P<0.01$, Fig. 4$)$. The size, area and volume of the vacuole in the presence of lycopene were 0.27 (SD 0.08) $\mu \mathrm{m}, 0.23(\mathrm{SD} 0.05) \mu \mathrm{m}^{2}$ and 0.01 (SD 0.00) $\mu \mathrm{m}^{3}$ respectively.

\section{Stability studies}

A significant $(P<0 \cdot 05)$ decrease in lycopene concentration was observed at 3 and $6 \mathrm{~h}$ as compared with $0 \mathrm{~h}$. The levels were reduced by 24.3 and $41.2 \%$ at 3 and $6 \mathrm{~h}$ respectively.
Effect of lycopene on glutathione and malonaldehyde levels

A significant fall $(55.7 \%, P<0.05)$ in glutathione level was observed in the presence of $30 \mathrm{~mm}$-galactose (control) in comparison with the normal group. The basal glutathione levels measured in the HLEC was $87.99 \mu \mathrm{g} / \mathrm{mg}$ protein whereas the glutathione content of the HLEC in the control group was found to be $38.91 \mu \mathrm{g} / \mathrm{mg}$ protein. No significant effect on glutathione level was seen with $5 \mu \mathrm{M}$-lycopene as compared with the control group. A positive modulation of glutathione levels was observed with $10 \mu \mathrm{m}$ as well as 20

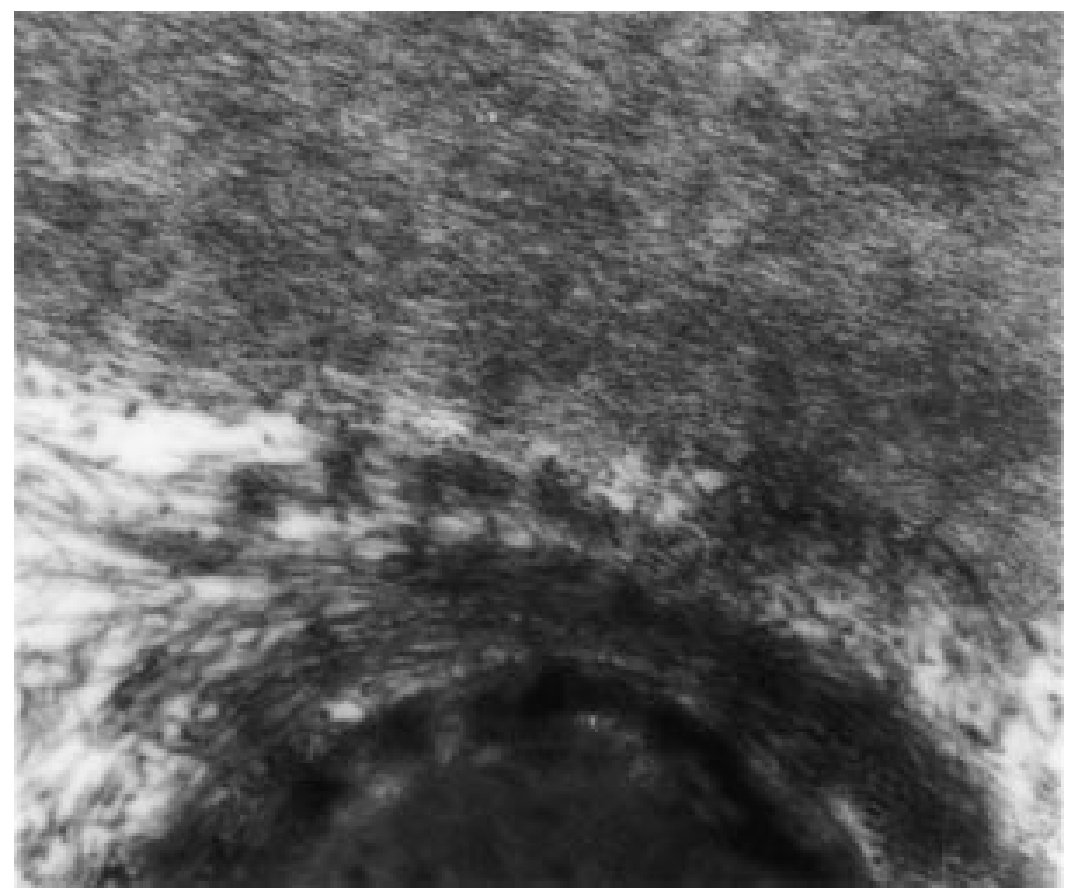

Fig. 2. Transmission electron micrograph of normal human lens epithelium cells (magnification $\times 15000$ ). For details of procedures, see p. 348 . 


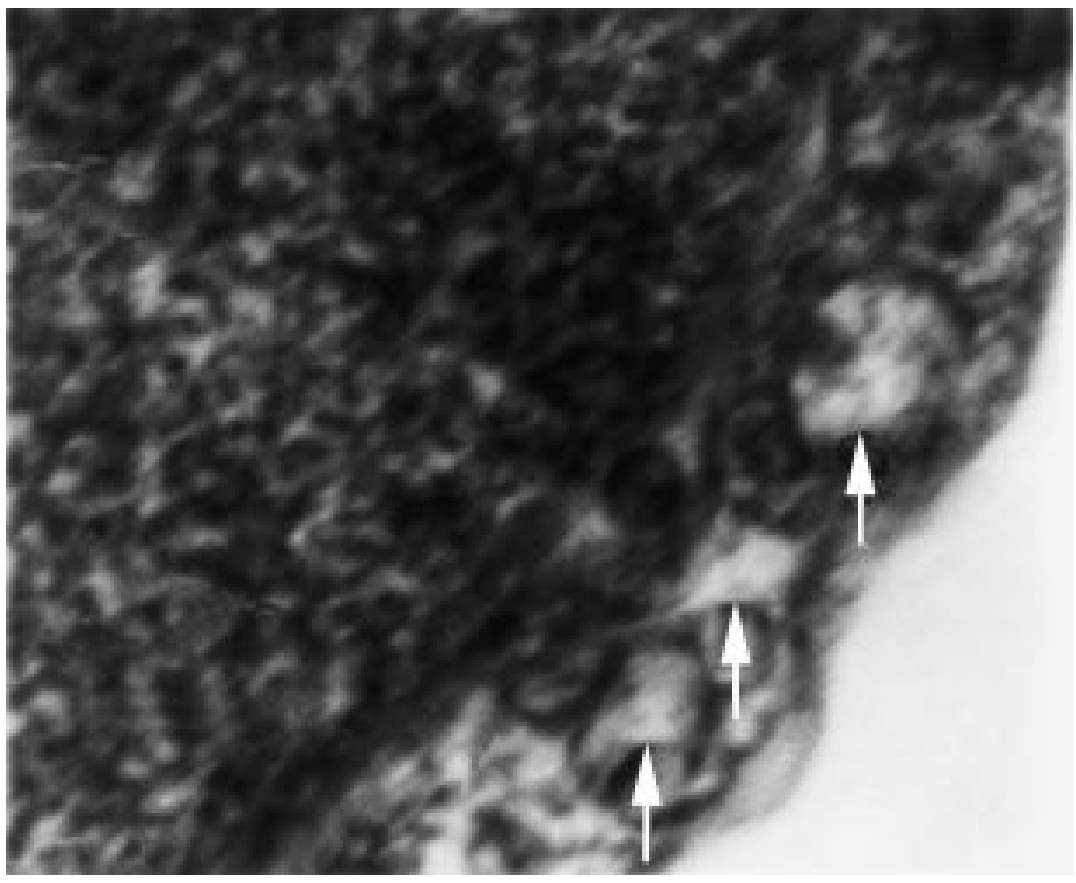

Fig. 3. Transmission electron micrograph of human lens epithelium cells incubated for $72 \mathrm{~h}$ in growth medium supplemented with $30 \mathrm{~mm}$-galactose (magnification $\times 15000$ ). Intact cell and nuclear membrane with condensation of chromatin. $\uparrow$, Vacuolization observed; $|-|, 0.4 \mu \mathrm{m}$. For details of procedures, see p. 348.

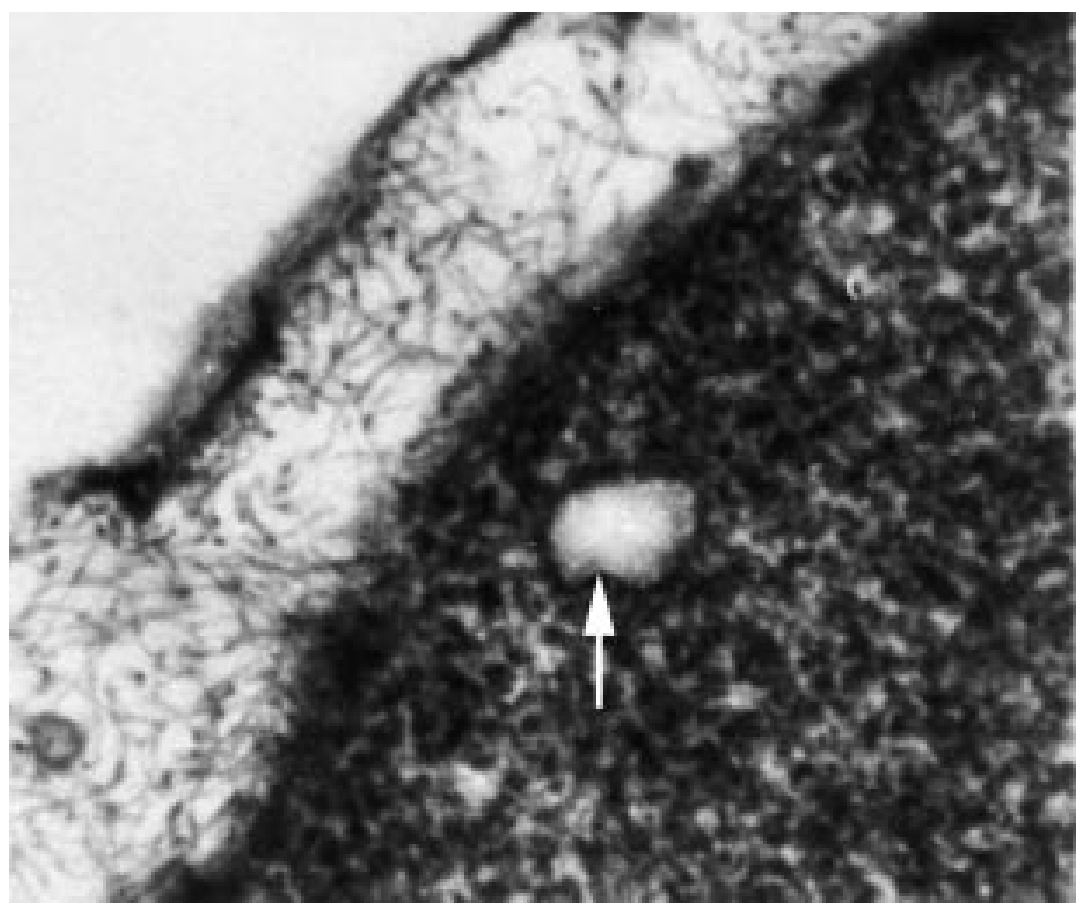

Fig. 4. Transmission electron micrograph of human lens epithelium cells incubated for $72 \mathrm{~h}$ in growth medium supplemented with $30 \mathrm{~mm}$-galactose and $10 \mu \mathrm{M}$-lycopene (magnification $\times 15000)$. $\uparrow$, Vacuoles decrease in number and size; $|-|, 0.4 \mu \mathrm{m}$. For details of procedures, see p. 348 . 


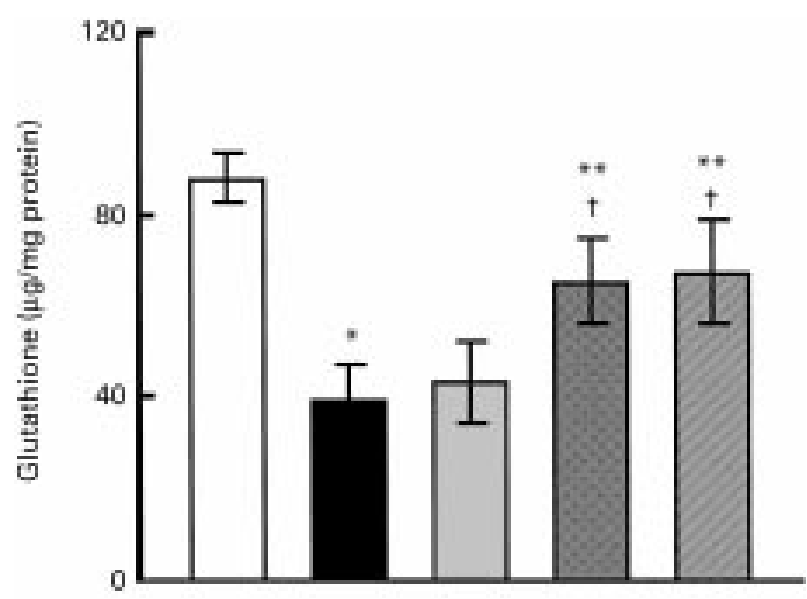

Fig. 5. Effect of lycopene on glutathione levels in human lens epithelial cells. Normal cells were cultured in Dulbecco's modified Eagle's medium: control, normal + sugar; test, normal + sugar + lycopene. $\square$, Normal; $\mathbf{\square}$, control; $\square$, test; $(5 \mu \mathrm{M})$; 畨, test $(10 \mu \mathrm{M})$; 四, test $(20 \mu \mathrm{M})$. For details of procedures, see p. 348. Values are means for six samples with standard deviations represented by vertical bars. Mean value was significantly different from normal value: ${ }^{\star} P<0.05$. Mean values were significantly different from control value: ${ }^{* \star} P<0.01$. Mean values were significantly different from test $(5 \mu \mathrm{m})$ value: $\dagger P<0.05$.

$\mu \mathrm{M}$-lycopene. However, the difference between the two groups was not significant. The glutathione levels increased to 65.30 and $67.20 \mu \mathrm{g} / \mathrm{mg}$ protein respectively (Fig. 5).

The basal MDA level in HLEC was found to be $1.4 \mathrm{nmol} /$ mg protein. On comparing the MDA levels in the control and the treatment groups, it was observed that incubation in the presence of galactose produced a significant increase in lipid peroxidation in the control group as evaluated by the MDA values $(2.6 \mathrm{nmol} / \mathrm{mg}$ protein). However, in the

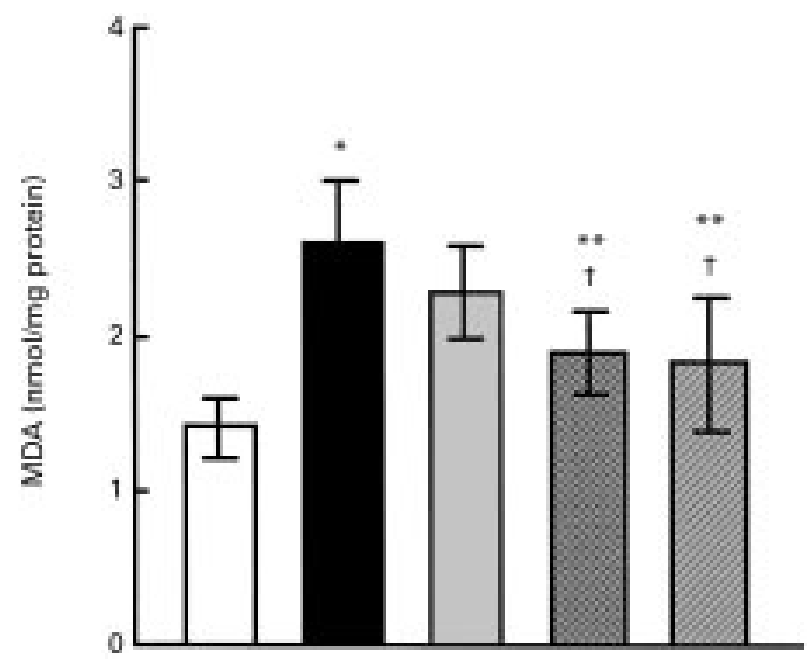

Fig. 6. Effect of lycopene on malonaldehyde (MDA) levels in human lens epithelial cells. Normal cells were cultured in Dulbecco's modified Eagle's medium: control, normal + sugar; test, normal +

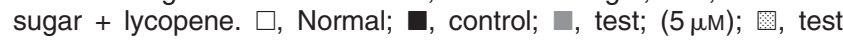
$(10 \mu \mathrm{M})$; 2 , test $(20 \mu \mathrm{M})$. For details of procedures, see p. 348. Values are means for six samples with standard deviations represented by vertical bars. Mean value was significantly different from normal value: ${ }^{*} P<0.05$. Mean values were significantly different from control value: ${ }^{* \star} P<0.01$. Mean values were significantly different from test $(5 \mu \mathrm{M})$ value: $† P<0.05$.
Table 1. Effect of lycopene on various antioxidant enzyme activities (units/mg protein) in human lens epithelial cells at $72 \mathrm{~h} \dagger$

(Mean values and standard deviations for six samples)

\begin{tabular}{|c|c|c|c|c|c|c|}
\hline & \multicolumn{2}{|c|}{ GSHPx-1‡ } & \multicolumn{2}{|c|}{ CAT§ } & \multicolumn{2}{|c|}{ GST\| } \\
\hline & Mean & SD & Mean & SD & Mean & SD \\
\hline Normalף & 1.21 & 0.22 & $1 \cdot 18$ & 0.47 & 0.09 & 0.001 \\
\hline Control" & $0.06^{\star \star \star}$ & 0.01 & 3.53 & 0.34 & $0.008^{\star * \star}$ & 0.003 \\
\hline Testף & $0.59^{* \star}$ & 0.09 & $1 \cdot 67^{*}$ & 0.54 & $0.06^{\star \star}$ & 0.009 \\
\hline
\end{tabular}

GSHPx, glutathione peroxidase; CAT, catalase; GST, glutathione $s$-transferase.

Mean values were significantly different from those of the control group; ${ }^{*} P<0.05,{ }^{* *} P<0.01$.

Mean values were significantly different from those of the normal group; ${ }^{* \star \star} P<0.01$.

†For details of procedures, see p. 348.

$\neq$ One unit GST is defined as the amount of enzyme required to conjugate $1 \mu \mathrm{mol} 1$-chloro-2,4-dinitrobenzene with glutathione/min.

$\S$ One unit catalase is defined as the amount of enzyme required to decompose $1 \mu \mathrm{mol} \mathrm{H}_{2} \mathrm{O}_{2} / \mathrm{min}$.

IOne unit GSHPx is defined as the amount of enzyme required to utilize $1 \mathrm{nmol} \mathrm{NADPH} / \mathrm{min}$ at $37^{\circ} \mathrm{C}$.

ๆ Normal, human lens epithelial cells in Dulbecco's modified Eagle's medium; control, normal + sugar; test, normal + sugar + lycopene.

presence of 10 and $20 \mu \mathrm{M}$ lycopene, lipid peroxidation was significantly reduced and malondiadehyde levels were found to be 1.90 and $1.82 \mathrm{nmol} / \mathrm{mg}$ protein respectively in the treated group as compared with control (Fig. 6).

\section{Effect of lycopene on antioxidant enzymes}

The effect of $10 \mu \mathrm{M}$-lycopene on different antioxidant enzymes (GST, GSHPx and CAT) is presented in Table 1. It was observed that in the control group the activities of GST and GSHPx enzymes were significantly reduced $(P<0.01)$ as compared with the normal group. In contrast to GSHPx and GST, a threefold increase in CAT activity was observed in the control group. Lycopene $(10 \mu \mathrm{M})$ significantly increased GST and GSHPx activity by 88 and $86 \%$ respectively as compared with the control group. In addition, lycopene decreased CAT activity significantly $(52 \%, P<0.05)$

\section{Discussion}

The HLEC are the metabolic unit of the lens and are responsible for maintaining its homeostasis and transparency. Being the most anterior part of the lens, it is the primary site of external insult that ultimately leads to cataract. Therefore, recent efforts are being directed to maintain HLEC in culture (Reddy et al. 1988). The establishment of lens epithelial cultures is of great importance, not only for the study of lens differentiation, but also to investigate the aetiology of cataract and to serve as a useful model for screening various anti-cataract agents.

Cataract is a multifactorial disease associated with several risk factors, diabetes being one of the most important risk factors (Kador \& Konoshita, 1984). Epidemiological studies suggest that nutritional antioxidants such as carotenoids delay the onset and progression of cataract (Jacques \& Chylack, 1991). Hence, interest in the anticataract potential of carotenoids is growing. Lycopene, a 
carotenoid that provides the familiar red colour to tomato products, is one of the major carotenoids present in the diet. Leutin and zeaxanthin are the carotenoids that have already been detected in the human lens (Yeum et al. 1999). No report showing the presence of lycopene in the human lens or aqueous humour is available. However, experimental studies clearly demonstrate the anti-cataract potential of lycopene in rats after oral feeding (Pollack et al. 1996). This suggests that lycopene does cross the blood-aqueous barrier. In the present paper, we have studied for the first time the anti-cataract potential of lycopene in human subjects.

Sugar-induced cataract in animal models has been extensively investigated, but there are few studies on human diabetic cataract (Varma et al. 1979). There is accumulating evidence that the activated polyol pathway in sugarinduced cataract is associated with oxidative stress (Miyoshi et al. 1999; Obrosova et al. 1999). The present study aimed to evaluate the antioxidant status of HLEC subjected to hypergalactosaemic conditions by assessing changes in levels of MDA, glutathione and antioxidant enzymes (GST, GSHPx, CAT). Studies were also conducted to see if these changes could be prevented by a nutritional antioxidant, lycopene. The minimum dose of lycopene $(10 \mu \mathrm{M})$ significantly preventing lipid peroxidation (MDA levels) and loss of glutathione levels was selected and its effect on antioxidant enzymes was evaluated.

The results indicate that exposure of HLEC to a high galactose concentration has an adverse effect on cell morphology, permeability characteristics and overall antioxidant status of the cell. Vacuolization was observed in HLEC in the presence of galactose. The vacuole formation, as observed by transmission electron microscopy, appears similar to the findings reported at the early stages in vivo in rat lens epithelium of galactose-fed animals (Jasmina et al. 1994). Formation of vacuoles is presumably due to the osmotic effect of intercellular accumulation of dulcitol. Supplementation with $10 \mu \mathrm{M}$-lycopene reduced the number of vacuoles. Present findings are consistent with those reported by Lin et al. (1991), who also observed vacuolization in HLEC incubated in the presence of galactose.

Glutathione plays very important role in various biochemical processes including lipid peroxidation and it provides a defence mechanism for tissue against the reactive oxygen species. Glutathione also forms one of the substrates for the two antioxidant enzymes GSHPx-1 and GST. The level of glutathione decreased significantly $(P<0.05)$ in HLEC in the presence of galactose. The levels were significantly $(P<0 \cdot 01)$ maintained in the presence of 10 and $20 \mu \mathrm{M}$-lycopene. The fall in glutathione levels could be attributed to the excessive diversion of NADPH, a co-substrate for aldose reductase enzyme, towards polyol synthesis and its consequent unavailability for glutathione reductase, leading to an overload on the cell antioxidant mechanisms. An increase in lipid peroxidation product in the presence of galactose clearly suggests membrane damage and involvement of reactive oxygen species in sugar cataracts. High levels of sugars are also known to auto-oxidize in the presence of trace metal ions and generate reactive oxygen species and dicarbonyl sugar derivatives (Wolff \& Dean, 1985). Significant $(P<0 \cdot 01)$ inhibition of lipid peroxidation and intact membrane by 10 and $20 \mu \mathrm{M}-1 y c o p e n e$ was observed. However, the exact mechanism by which lycopene prevents lipid peroxidation is not clear. Lycopene, due to its poor solubility and perhaps in the form of microcrystalline solution, might stick to the outside of the cell and prevent exposure of the lens epithelial cells to reactive oxygen species. However, the exact site of action of lycopene could not be established as the intracellular levels of lycopene were not measured.

A fall in enzyme activities of GSHPx-1 and GST in the control group was observed which might be correlated to decreased availability of its substrate, glutathione. However, lycopene treatment prevented the decrease in glutathione level and positively modulates GSHPX-1 and GST activities.

CAT plays an important role in lens defence mechanisms against the harmful effects of oxygen free-radicals in biological systems (Spector, 1995). The most interesting finding of the present study is the threefold increase in activity of CAT within $72 \mathrm{~h}$ in the presence of galactose in incubation medium and its down-regulation by lycopene. In the control group, enhanced CAT activity clearly suggests overproduction of $\mathrm{H}_{2} \mathrm{O}_{2}$ in the presence of galactose. On addition of lycopene to the culture medium, it was observed that CAT activity decreased significantly $(P<0.05)$. Decreased activity of CAT in the presence of lycopene could be explained either through inhibition of autoxidation of galactose itself leading to reduced generation of $\mathrm{H}_{2} \mathrm{O}_{2}$, or by the increased utilization of $\mathrm{H}_{2} \mathrm{O}_{2}$ by enzymes GSHPX-1 and GST. Increased GSHPX-1 and GST activities in presence of lycopene could probably be a reflection of the same processes. It is also possible that like pyruvate, a physiological antioxidant, lycopene may act through the peroxidative decarboxylation pathway decomposing $\mathrm{H}_{2} \mathrm{O}_{2}$ into non-toxic acetic acid, water and $\mathrm{CO}_{2}$ (Varma et al. 1990).

The results obtained from the present study indicates that lycopene offers protection to the lens by modulating various antioxidant variables and could be a potential anti-cataract agent. The present study is consistent with epidemiological evidence of the protective role of lycopene against oxidative damage in the epithelium cortex of the human lens (Lyle et al. 1999; Yeum et al. 1999). Although lycopene is quite unstable in an aqueous medium, adequate levels were found to be present at $3 \mathrm{~h}(0.76 \mathrm{~mm})$ and $6 \mathrm{~h}$ $(0.59 \mathrm{~mm})$. Though lycopene levels at $6 \mathrm{~h}$ were significantly less than at $0 \mathrm{~h}(P<0 \cdot 05)$, it appears from the results of the present study that lycopene offers beneficial effects even at this low concentration. However, further studies on lycopene regarding its pharmacokinetics in the human eye should be contemplated for a better understanding of the mechanism and site of action of lycopene.

\section{Acknowledgements}

This work was supported by grants from Department of Biotechnology (DBT), India. 


\section{References}

Aebi H (1974) Catalase. In Methods of Enzymatic Analysis, vol. 2, [HE Bergmayer, editor]. London: Academic Press.

Bermbach G, Mayer U \& Naumann G (1991) Human lens epithelial cells in tissue culture. Experimental Eye Research 52, $113-119$.

Clinton SK (1998) Lycopene: Chemistry, biology and implications for human health and disease. Nutrition Reviews 56, 35-51.

Collier A \& Small M (1993) The role of polyol pathway in diabetes mellitus. Journal of Hospital Medicine 45, 38-40.

Di Mascio P, Kaiser S \& Sies H (1989) Lycopene is the most efficient biological carotenoid singlet oxygen quencher. Archives of Biochemistry and Biophysics 274, 1-7.

Eguchi G \& Okada TS (1971) Ultrastructure of the differentiated colony derived from a single isolated chondrocyte in in vitro culture. Development Growth and Differentiation 12, 297-312.

Hebig H (1974) Glutathione-S-transferase, the first enzymatic step in mercapturic acid formation. Journal of Biochemistry 249, $7130-7134$.

Jacques PF \& Chylack LT (1991) Epidemiological evidence of a role for the antioxidant vitamins and carotenoids in cataract prevention. American Journal of Clinical Nutrition 53, 352.

Jasmina BM, Bekhor I, Weiss MH \& Zlokovic BV (1994) Galactose induced cataract formation in guinea pigs: Morphological changes and accumulation of galactitol. Investigative Ophthalmology and Visual Science 35, 804-811.

Kador PF \& Kinoshita JH (1984) Diabetic and galactosemic cataracts. Ciba Foundation Symposium 106, 110-115.

Lin LR, Reddy VN, Giblin FJ, Kador PF \& Kinoshita JH (1991) Polyol accumulation in cultured human lens epithelial cells. Experimental Eye Research 52, 93-100.

Lowry OH, Rosebrough NJ \& Farr AI (1951) Protein measurements with the Folin phenol reagent. Journal of Biological Chemistry 193, 265-275.

Lyle BJ, Mares Perlman JA, Klain R, Palta M, Bowen PE, Palta M, Bowen PE \& Greger JL (1999) Serum carotenoids and tocopherols and incidence of age related nuclear cataract. American Journal of Clinical Nutrition 69, 272-279.

Miyoshi EKN, Fukuda M \& Akagi Y (1999) Cataract formation through the polyol pathway is associated with free radical production. Experimental Eye Research 68, 457-464.

Moron MS, Depierre JW \& Manmerik B (1979) Level of glutathione, glutathione reductase and glutathione-S-transferase activity in rat lung and liver. Biochimica et Biophysica Acta 82 , $67-78$.

Obrosova IG, Fathallah L \& Lang HJ (1999) Interaction between osmotic and oxidative stress in diabetic precataractous lens. Biochemical Pharmacology 58, 1945-1954.

Ohkawa H, Ohishi N \& Yagi K (1979) Assay of lipid peroxide in animal tissue by thiobarbituric acid reaction. Analytical Biochemistry 95, 351-358.

Paglia DE \& Valentine WN (1967) Studies on the quantitative and qualitative characterization of erythrocyte peroxidase. Journal of Laboratory and Clinical Medicine 2, 158.

Pollack A, Oren P, Stark AH, Eisner Z, Nyska A \& Madar Z (1999) Cataract development in sand and galactosemic rats fed a natural tomato extract. Journal of Agriculture Food Chemistry 47, 5122-5126.

Pollack A, Madar Z, Eisner Z, Nyska A \& Oren P (1996-1997) Inhibitory effect of lycopene on cataract development in galactosemic rats. Metabolic Pediatric Systemic Ophthalmology 1920, 31-36.

Reddy VN, Agata K \& Sawada K (1991) Study of crystallin expression in human lens epithelial cell during differentiation in culture and in non-lenticular tissues. Experimental Eye Research 53, 367-374.

Reddy VN, Arita T \& Lin LR (1988) Differentiation of human lens epithelial cells in tissue culture. Experimental Eye Research 47, 905-910.

Spector A (1995) Oxidative stress induced cataract: Mechanism of action. FASEB Journal 9, 1173-1182.

Stahl W, Sundquist AR, Hanusch M, Schwarz W \& Sies H (1993) Separation of beta-carotene and lycopene geometrical isomers in biological samples. Clinical Chemistry 39, 810-814.

Varma SD, Devamanoharan PS \& Morris SM (1990) Photoinduction of cataracts in rat lens in vitro: preventive effect of pyruvate. Experimental Eye Research 50, 805-812.

Varma SD, Schocket SS \& Richards RD (1979) Implications of aldose reductase in cataract in human diabetes. Investigative Ophthalmology and Visual Science 3, 237-241.

Wolff SP \& Dean RT (1985) Glucose autoxidation and protein modifications. The potential role of autoxidative glycosylation in diabetes. Biochemical Journal 245, 243-250.

Yeum KJ, Shang FM, Schalch WM, Russell RM \& Taylor A (1999) Fat soluble nutrient concentrations in different layers of human cataractous lens. Current Eye Research 19, 502505. 